\title{
The novel histone de acetylase 6 inhibitor, MPTOG211, ameliorates tau phosphorylation and cognitive deficits in an Alzheimer's disease model
}

\author{
Sheng-Jun Fan ${ }^{1}$, Fang-l Huang ${ }^{1}$, Jing-Ping Liou ${ }^{2}$ and Chia-Ron Yang (1)
}

\begin{abstract}
Alzheimer's disease (AD) is a dreadful neurodegenerative disease that leads to severe impairment of cognitive function, leading to a drastic decline in the quality of life. The primary pathological features of AD include senile plaques (SPs) and intracellular neurofibrillary tangles (NFTs), comprising aggregated amyloid $\beta$ (A $\beta$ ) and hyperphosphorylated tau protein, respectively, in the hippocampus of AD patients. Histone deacetylase 6 (HDAC6) is a key enzyme in this neurodegenerative disease, in particular, as it relates to tau hyperphosphorylation. This study aimed to investigate the protective effects and mechanism of the novel HDAC6 inhibitor, MPTOG211, using an AD model. Our results indicated that MPTOG211 significantly reduced tau phosphorylation and aggregation, the processes highly correlated with the formation of NFTs. This HDAC6 inhibitory activity resulted in an increase in acetylated Hsp90, which decreased Hsp90 and HDAC6 binding, causing ubiquitination of phosphorylated tau proteins. In addition, a significant increase of phospho-glycogen synthase kinase-3 $\beta$ (phospho-GSK3 $\beta$ ) on Ser9 (the inactive form) through Akt phosphorylation was associated with the inhibition of phospho-tau Ser396 in response to MPTOG211 treatment. In AD in vivo models, MPTOG211 appeared to ameliorate learning and memory impairment in animals. Furthermore, MPTOG211 treatment reduced the amount of phosphorylated tau in the hippocampal CA1 region. In summary, MPTOG211 treatment appears to be a promising strategy for improving the AD phenotypes, including tau hyperphosphorylation and aggregation, neurodegeneration, and learning and memory impairment, making it a valuable agent for further investigation.
\end{abstract}

\section{Introduction}

Alzheimer's disease (AD) is one of the most common neurodegenerative diseases, accounting for more than $80 \%$ of dementia cases worldwide. AD leads to the progressive loss of mental capacity and behavior, with a functional decline in the ability to learn. Several hypotheses have been extended to explain $\mathrm{AD}$, including the cholinergic

Correspondence: C-R. Yang (cryang@ntu.edu.tw)

${ }^{1}$ School of Pharmacy, College of Medicine, National Taiwan University, Taipei, Taiwan

${ }^{2}$ School of Pharmacy, College of Pharmacy, Taipei Medical University, Taipei, Taiwan

Edited by D. Bano hypothesis, which was the first theory. The cholinergic hypothesis posits that the primary problem is a deficit in acetylcholine, caused by the death of cholinergic neurons ${ }^{1}$. Another primary hypothesis is that hyperactivation of the $\mathrm{N}$-methyl-D-aspartate (NMDA) receptor by glutamate leads to the production of free radicals and the activation of enzymes that contribute to the death of neuronal cells ${ }^{2}$. Accordingly, four drugs approved by the Food and Drug Administration are used to treat cognitive manifestations of $\mathrm{AD}$, namely, the acetylcholine esterase inhibitors revastigmine, galantamine, and donepezil, as well as the NMDA receptor antagonist, memantine. These drugs have been revealed to reduce the progression of cognitive symptoms; 
however, the benefits are limited in more than half of the patients who take these drugs ${ }^{2,3}$. Thus new drug development for AD treatment is an urgent issue. Recent studies have focused on the amyloid and tau proteins as therapeutic targets. Although the detailed mechanisms remain unclear, present evidence suggests that the expression of these two markers may be linked ${ }^{2,4}$. For example, amyloid $\beta(A \beta)$ not only spontaneously aggregates into the soluble oligomers, forming plaques resulting in network dysfunction, but also increases the accumulation of tau aggregates and the development of neurofibrillary tangles (NFTs), which leads to synaptic dysfunction and eventually neuronal $\operatorname{loss}^{2,4}$. Therefore, the recent treatment strategies have attempted to manage $\mathrm{AD}$ by modulating the functions of these two major proteins.

Histone deacetylase 6 (HDAC6) belongs to the HDAC family, and its structure contains a cytoplasmic anchoring domain, which mediates its stable anchorage in the cytoplasm. The enzymatic activity of HDAC6 is exerted on tubulin, heat-shock protein 90 (Hsp90), and cortactin substrates; thus it has been identified as a key regulator of the cytoskeleton and cell migration ${ }^{5}$. Present studies have demonstrated that HDAC6 levels significantly increase in the hippocampus and cortex of the $\mathrm{AD}$ brain, and tubulin acetylation is reduced in the neurons containing NFTs ${ }^{6}$. While the detailed mechanisms of these processes remain unknown, HDAC6 appears to be involved in the process of tau hyperphosphorylation ${ }^{6,7}$. Tau is predominantly expressed in neurons where its primary function is to promote microtubule stability ${ }^{1,4}$; however, the hyperphosphorylation of tau has been suggested to impair its ability to bind and stabilize microtubules, thus promoting tau self-assembly and aggregation ${ }^{2,4}$. In addition to hyperphosphorylation, tau becomes abnormally accumulated in dystrophic neuritis around senile plaques (SPs) and in NFTs of the AD brain ${ }^{2}$. Recent studies have indicated that HDAC6 interacts with tau in human brain tissues, and the inhibition of HDAC6 attenuates tau phosphorylation at T231, a critical regulatory site for tau function; however, it does not disrupt the HDAC6-tau interaction $^{6}$. Furthermore, HDAC6 inhibition also appeared to downregulate $A \beta$ aggregation ${ }^{8}$ and improve cognition in an $\mathrm{AD}$ mouse model ${ }^{7}$. In addition, a recent study indicated that mice lacking HDAC6 survive well and develop normally ${ }^{9}$, suggesting that the pharmacological inhibition of HDAC6 may not cause severe side effects. Collectively, these results suggest that HDAC6 may be a novel target of AD.

The present study investigated the effect and mechanism of the novel HDAC6 inhibitor, MPT0G211 (Nhydroxy-4-((quinolin-8-ylamino)methyl)benzamide), on neuronal protection and cognitive function of $\mathrm{AD}$ models. We found that MPT0G211 significantly inhibited tau phosphorylation on Ser396, Ser404, and phosphorylated tau (p-tau) aggregation. The HDAC6 inhibitory activity of MPT0G211 resulted in an increase in acetylated Hsp90, which decreased HDAC6-Hsp90 binding, and led to the ubiquitination of phosphorylated tau. In addition, a significant increase in phospho-glycogen synthase kinase-3 $\beta$ (phospho-GSK3 $\beta$ ) on Ser9 (the inactive form) through Akt phosphorylation was associated with the inhibition of phospho-tau Ser396 in response to MPT0G211 treatment. In AD in vivo models, MPT0G211 treatment reduced the time spent by animals in finding the platform and closed arm in the Morris water maze and elevated plus maze test and reduced the amount of phosphorylated tau in the hippocampal CA1 region, which is related to learning and memory ${ }^{10}$. Furthermore, MPT0G211 appeared to be able to cross the blood-brain barrier (BBB) after oral administration. Collectively, these results demonstrate that MPT0G211 has high potential as a treatment strategy for AD.

\section{Results \\ HDAC6 inhibition and selectivity by MPT0G211}

Our previous study demonstrated that MPT0G211 (Fig. 1a) exhibited potent HDAC6 inhibition $\left(\mathrm{IC}_{50}\right.$ value $=0.291 \mathrm{nM})$ and was 1000-fold more selective for HDAC6 compared with the other HDAC isoforms ${ }^{11}$. In addition, MPT0G211 concentration-dependently increased the acetylation of $\alpha$-tubulin in SH-SY5Y and Neuro-2a cells, the common used neuronal cell lines in the study of $\mathrm{AD}$, at concentrations ranging from 0.1 to 1 $\mu \mathrm{M}$ without affecting the acetylation of histones, which is consistent with the selective inhibition of HDAC6 (Fig. 1b, c). Similar results for the acetylation of $\alpha$-tubulin versus control were obtained using another HDAC6 inhibitor, ACY-1215. SAHA, a non-selective HDAC inhibitor, treatment both significantly increased the acetylation of $\alpha$-tubulin and histones. Nevertheless, $1 \mu \mathrm{M}$ ACY-1215 treatment caused less acetylation of $\alpha$-tubulin; these results were consistent with MPT0G211 exhibiting more potent HDAC6 inhibition than ACY-1215 ${ }^{11}$. In addition, MPT0G211 treatment did not result in any significant cytotoxicity in SH-SY5Y and Neuro-2a cells after $24 \mathrm{~h}$ (Fig. 1d), suggesting that the concentrations used in this study $(0.01-1 \mu \mathrm{M})$ did not cause cell death.

\section{Inhibition of tau phosphorylation and aggregation}

$\mathrm{AD}$ is characterized by the presence of SPs, which are extracellular aggregates composed of $A \beta$ peptides, and NFTs, which are intracellular aggregates composed of hyperphosphorylated $\mathrm{tau}^{2}$. In addition, $\mathrm{A} \beta$ can increase the accumulation of tau aggregates as well as NFTs, leading to synaptic dysfunction and eventually neuronal death $^{2,7}$. Therefore, tau phosphorylation was measured in SH-SY5Y and Neuro-2a cells transfected with the pCAX amyloid precursor protein 695 (APP 695) plasmid with 
A<smiles>c1ccc2ncccc2c1</smiles><smiles>NCc1ccc(C(=O)O)cc1</smiles>

M.W. 293.32
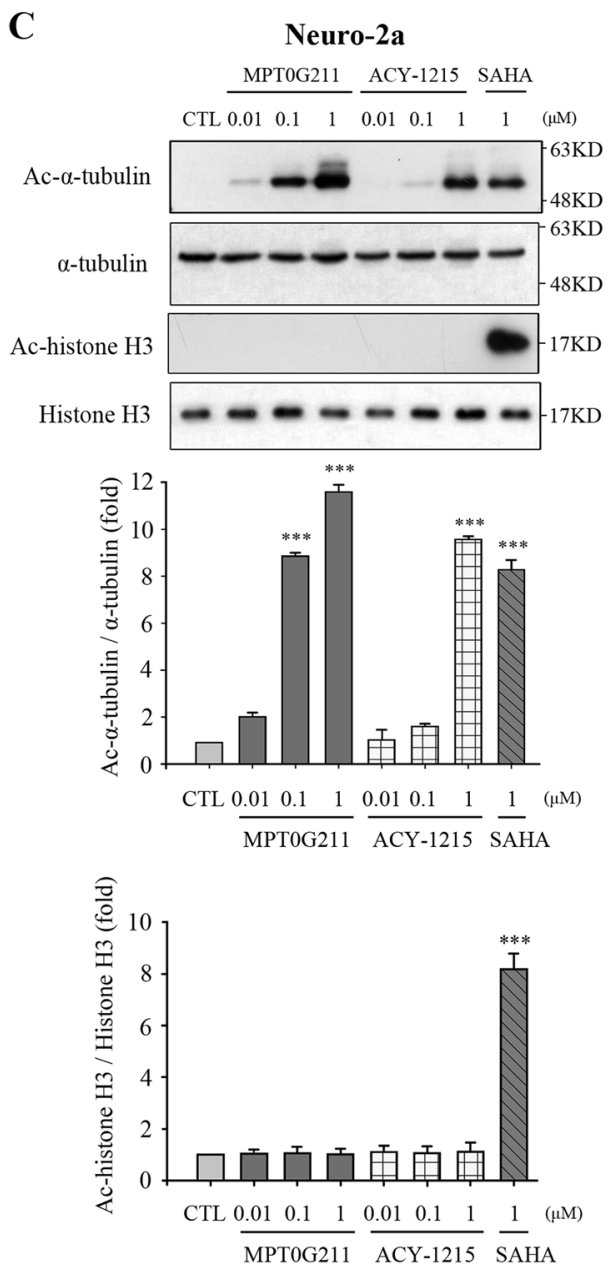

SH-SY5Y
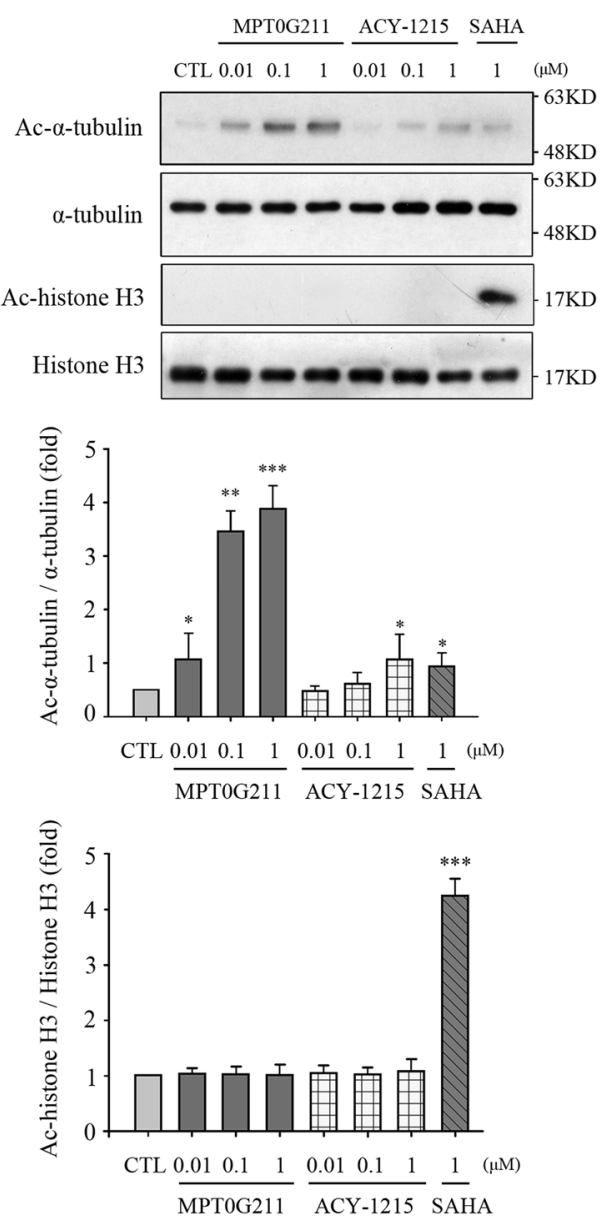

D
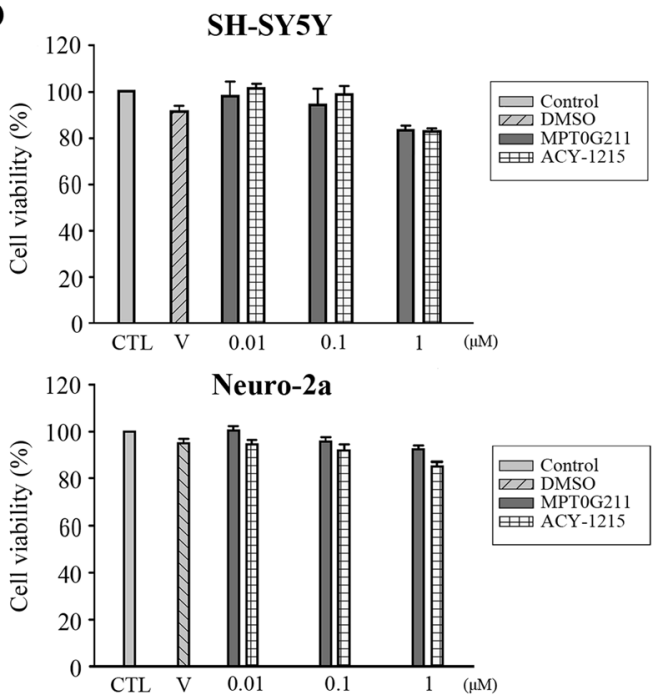

Fig. 1 MPTOG211 exhibited potent HDAC6 inhibition. a The structure of MPTOG211. b, c SH-SY5Y or Neuro-2a cells were treated with the indicated concentrations of MPTOG211, ACY-1215, or SAHA for $24 \mathrm{~h}$, and the whole-cell lysate was subjected to western blotting with the indicated antibodies. d SH-SY5Y and Neuro-2a cells were incubated for $24 \mathrm{~h}$ with or without the indicated concentrations of MPTOG211 or ACY-1215. Cell viabilities were determined by MTT assay. The results represent the mean \pm SEM of three independent experiments; ${ }^{*} p<0.05,{ }^{* *} p<0.01$ and ${ }^{* * *} p<$ 0.001 compared with controls 


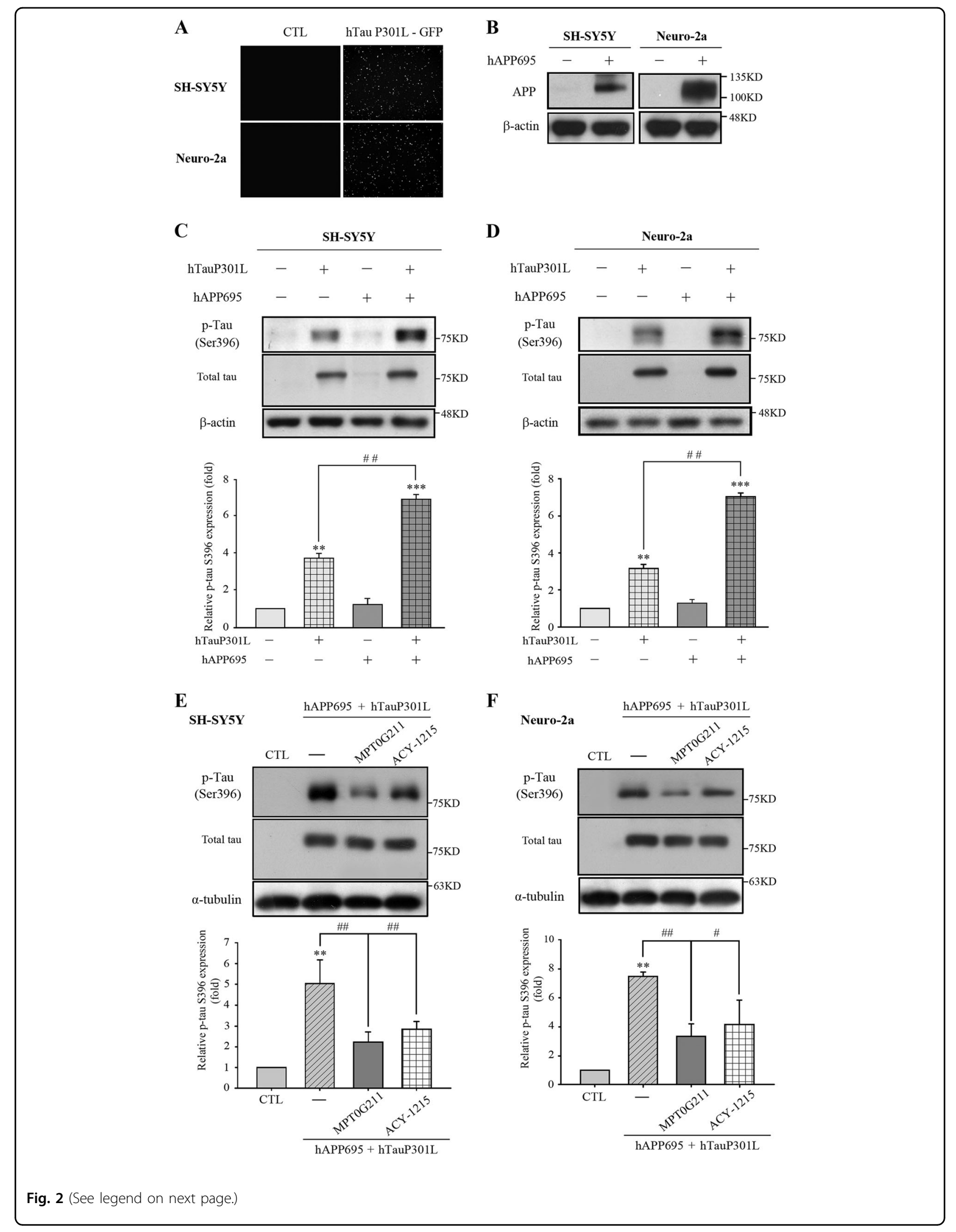


(see figure on previous page)

Fig. 2 MPTOG211 significantly inhibited tau phosphorylation. a pRK5-EGFP-Tau P301L was used to transfect SH-SY5Y or Neuro-2a cells for 24 h; then cells were photographed by fluorescence microscopy. Images represented magnification at $\times 100$. b Cells were transfected with pCAX APP 695 for $24 \mathrm{~h}$, harvested, and cell lysates were subjected to Western blotting. c, d SH-SY5Y and Neuro-2a cells were transfected with pCAX APP 695 and/or pRK5-EGFP-Tau P301L for $24 \mathrm{~h}$. Cell lysates were prepared for western blot analysis of the indicated proteins. e, $\mathbf{f}$ Cells were transfected with pCAX APP 695 and PRK5-EGFP-Tau P301L for $24 \mathrm{~h}$ and were then incubated with or without MPT0G211 or ACY-1215 (0.1 $\mu$ M) for another $24 \mathrm{~h}$. Cell lysates were subjected to western blot analysis using the indicated antibodies. Results are presented as the mean \pm SEM from three independent experiments. ${ }^{* *} p<0.01,{ }^{* * *} p<0.001$ compared with the control group; ${ }^{\#} p<0.05,{ }^{\# \#} p<0.01$ compared with the indicated groups

tyrosine/histidine mutations of APP and the pRK5-EGFPTau P301L plasmid, which encodes human mutant P301L-tau, respectively ${ }^{12,13}$. The efficiency of the transfections was determined by fluorescence microscopy (Fig. 2a) and western blot (Fig. 2b). The phosphorylation of tau Ser396 was significantly increased in the cells transfected with P301L, and tau was hyperphosphorylated in cells cotransfected with hAPP 695 in SH-SY5Y and Neuro-2a cells (Fig. 2c, d). Furthermore, we determined whether MPT0G211 treatment could inhibit tau phosphorylation. As reported, MPT0G211 treatment significantly inhibited the phosphorylation of tau Ser396 in both cell lines (Fig. 2e, f). ACY-1215 treatment exhibited a similar inhibition; however, it was less efficient than MPT0G211. It is known that hyperphosphorylation also increases the capacity of tau assembles to form aggregates from oligomers to fibrils, eventually leading to their deposition as NFTs and causing neuronal dysfunction, including reduced mitochondrial respiration, altered mitochondrial dynamics, and impaired axonal transport ${ }^{14}$. Accordingly, we used an established method to determine whether MPT0G211 reduces the polymerization of phosphorylated tau ${ }^{15}$; 17-AAG (17-allylamino-17-demethoxygeldanamycin), an inhibitor of Hsp90, was used as positive control. As demonstrated, cytosolic levels of tau associated with membranes and, in aggregates, were significantly increased in SH-SY5Y cells cotransfected with hAPP 695 and hTau P301L (Fig. 3a). Treatment of the transfectants with MPT0G211 significantly reduced the levels of aggregated tau (Fig. 3a). In addition, using flow cytometry to detect sub-G1 peak and annexin V-positive cells in apoptosis, we observed that MPT0G211 treatment significantly inhibited the plasmid transfection-induced sub-G1 population and annexin V-positive apoptotic cells increase in the neuronal cells (Fig. 3b-d). These results suggest that MPT0G211 not only inhibited tau phosphorylation and aggregation but also downregulated tau aggregation associated with the neuronal cell apoptosis.

\section{Neuroprotective effects of MPT0G211}

As previously described, a primary pathologic component of $\mathrm{AD}$ is the formation of NFTs composed of hyperphosphorylated tau. Thus promoting the removal of these p-tau species may be a relevant therapeutic strategy.
Although the significance of the chaperones that interplay in $\mathrm{AD}$ pathology remains unclear, increasing evidence suggests that Hsp-ubiquitin-proteasome system (UPS)mediated aggregate clearance plays a pivotal role in the AD pathology and further emphasizes the role of Hsp90 as a mediator of tau protein regulation and degradation ${ }^{16}$. Since Hsp90 is a substrate of HDAC6, the downregulation of the expression or activity of HDAC6 has been reported to promote Hsp90 acetylation, thereby favoring tau degradation ${ }^{17,18}$. Therefore, we explored the neuroprotective mechanism of MPT0G211 and whether it acts through Hsp90 and UPS modulation. As indicated, plasmid cotransfection significantly increased HDAC6/Hsp90 binding (Fig. 4a). In addition, MPT0G211 treatment clearly enhanced the acetylation of Hsp90, which caused the downregulation of HDAC6/Hsp90 binding (Fig. 4a). In cells treated with MPT0G211, coimmunoprecipitation of ubiquitin with p-tau (Ser396) clearly increased (Fig. 4b), and the level of polyubiquitinated proteins significantly accumulated (Fig. 4c). In addition, proteasome inhibitor MG132 treatment significantly reversed the MPT0G211induced inhibition of p-tau at Ser396 in both cell lines (Fig. 4d). These results suggest that MPT0G211 inhibited HDAC6/Hsp90 binding and caused subsequent proteasomal degradation of polyubiquitinated proteins.

Moreover, we identified whether MPT0G211 also contributed to the attenuation of tau phosphorylation. Previous studies have indicated that GSK3 $\beta$ and cyclindependent kinase 5 (CDK5) are tau kinases, and these proteins have been proposed to contribute to the pathogenesis of $\mathrm{AD}^{19,20}$. In addition, the activity of GSK3 $\beta$ is dependent on its phosphorylation at specific sites, including Ser9 and Tyr216, which can inhibit or increase GSK3 $\beta$ activity, respectively ${ }^{19}$. Therefore, we evaluated CDK5 and phospho-GSK3 $\beta$ on Ser9 and Tyr216 expression in response to plasmid cotransfection and MPT0G211 treatment. As demonstrated, phosphorylation of tau Ser396 and Ser404 significantly increased in the cells transfected with the plasmids, but no increases or mild increases in the phosphorylation of other sites (Ser262 and Ser356) were observed (Fig. 5a). MPT0G211 treatment significantly attenuated the phosphorylation of tau Ser396 and Ser404 in both cell lines (Fig. 5a); no marked changes in CDK5, p25, or p35 expression were 
A

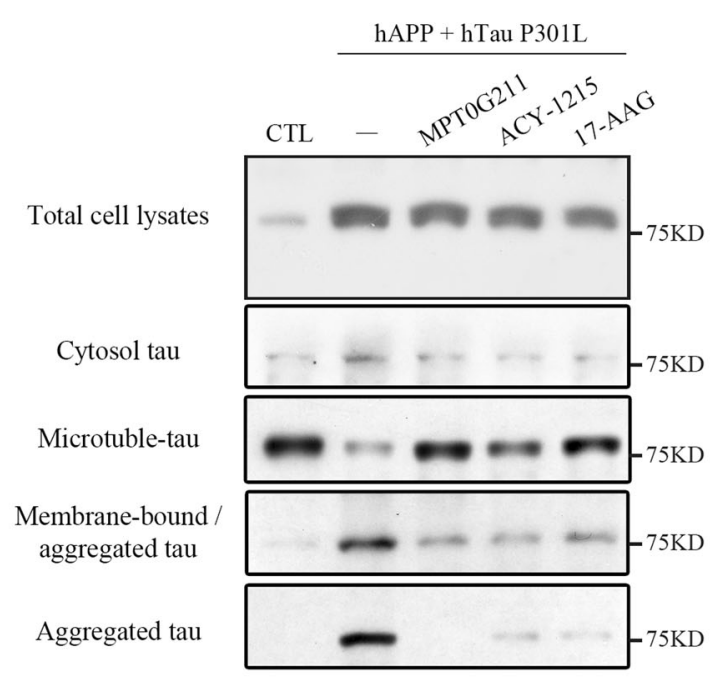

B

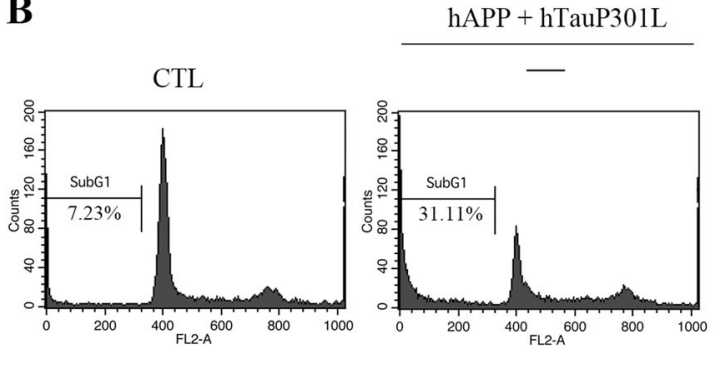

hAPP + hTauP301L
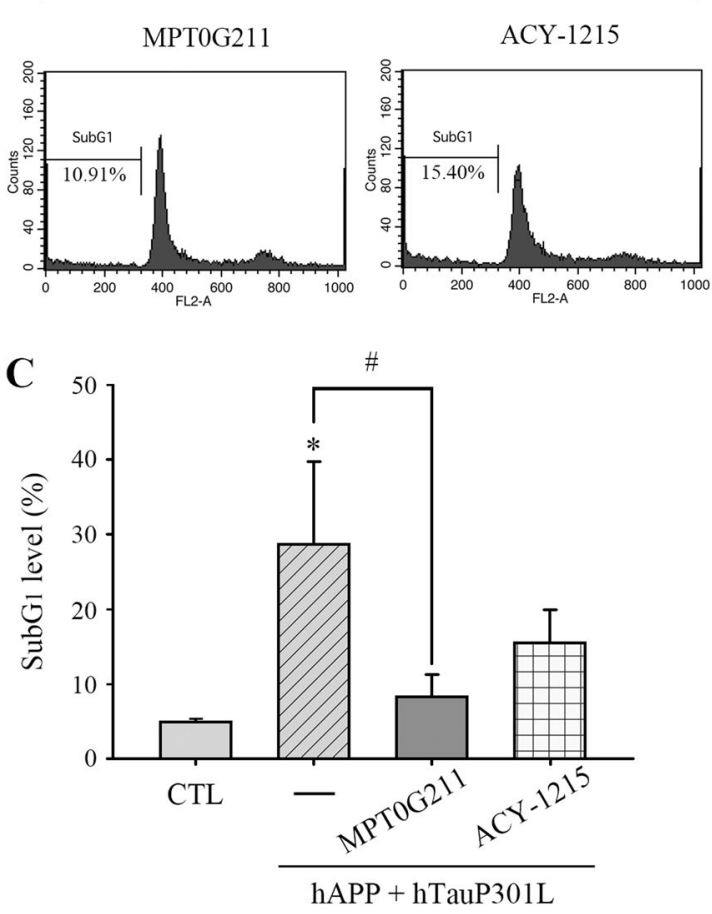

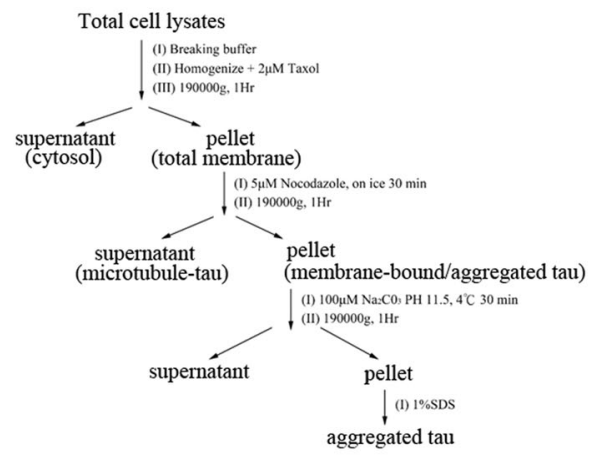

D

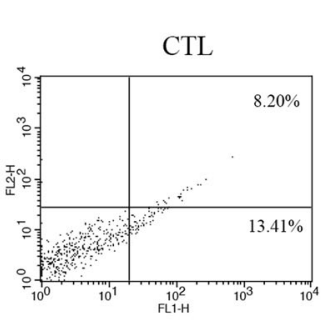

hAPP + hTauP301L

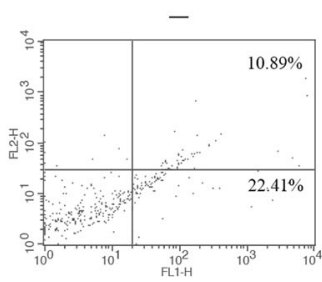

hAPP + hTauP301L

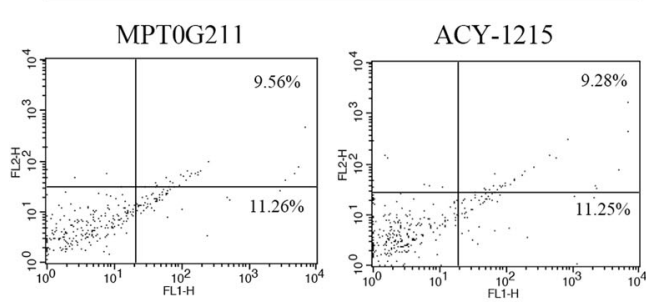

$\mathbf{E}$

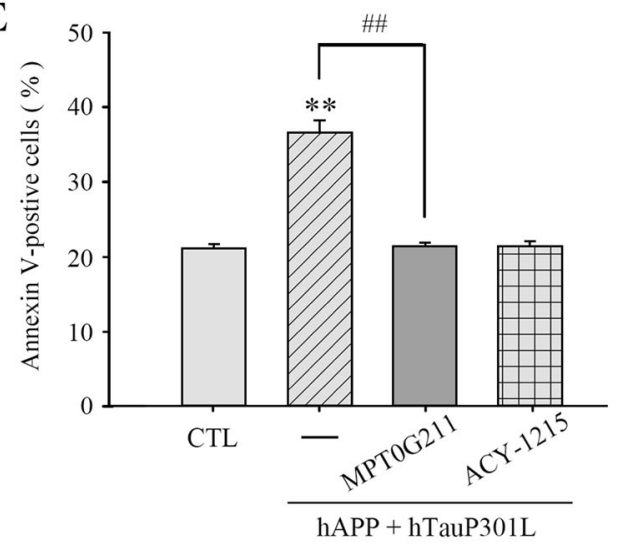

Fig. 3 (See legend on next page.) 
(see figure on previous page)

Fig. 3 MPTOG211 significantly attenuated tau aggregation and apoptosis induced by phosphorylated tau. a SH-SY5Y cells were transfected with PCAX APP 695 and pRK5-EGFP-Tau P301L for $24 \mathrm{~h}$ and then incubated with MPTOG211 or ACY-1215 (0.1 $\mu \mathrm{M})$ for another $24 \mathrm{~h}$. The fractionation scheme used to separate different cellular pools of tau, and the western blot analysis of the effects of the compounds on tau pools generated using the fractionation scheme are presented. b, d SH-SY5Y cells were transfected for $24 \mathrm{~h}$ with pCAX APP 695 and pRK5-EGFP-Tau P301L, incubated with or without MPTOG211 or ACY-1215 (0.1 $\mu \mathrm{M})$ for another $24 \mathrm{~h}$, and then the cells were fixed and stained by propidium iodide (b) or annexin V/PI double staining (d) and analyzed by flow cytometry. c, e Percentages of the subG1 phase (c) or annexin V-positive cells (e) in response to drug treatment as explained in (b). Results are presented as the mean \pm SEM. ${ }^{*} p<0.05$ and ${ }^{* *} p<0.01$ compared with the control group; ${ }^{\#} p<0.05$ and ${ }^{\# \#} p$ $<0.01$ compared with the indicated groups

associated with MPT0G211-induced phospho-tau downregulation; however, significant phospho-GSK3 $\beta$ increases on Ser9 through Akt phosphorylation were associated with the inhibition of phospho-tau Ser396 in response to MPT0G211 treatment (Fig. 5b). In addition, a decrease in phospho-GSK3 $\beta$ on Ser216 was also observed. Accumulating evidence suggests that $A \beta$ promotes tau phosphorylation through several mechanisms, including the activation of GSK3 $\beta^{21}$. Therefore, tau phosphorylation was measured in both cell lines treated with $A \beta_{1-40}$. As reported, $A \beta_{1-40}$-induced significant $p$-GSK3 $\beta$ (Ser9) attenuation and increase in p-tau (Ser396); MPT0G211 treatment diminished GSK3 $\beta$ activity and $A \beta_{1-40}$-induced tau phosphorylation (Fig. 5c).

\section{MPTOG211 ameliorates learning and memory impairments in an animal model}

We further evaluated whether MPT0G211 treatment ameliorates learning and memory impairment. Using the Morris water maze test, we first evaluated the learning ability by training rats with a hidden platform. Triple transgenic $(3 \times \mathrm{Tg}-\mathrm{AD})$ mice, which harbor $\mathrm{APP}_{\text {Swe }}$ and tau $_{\mathrm{P} 301 \mathrm{~L}}$ mutant transgenes, are known to develop neuropathologies, such as plaque and tangles ${ }^{19}$. In this study, we used these mice to evaluate the neuroprotective effect of MPT0G211, and memantine (a drug that is approved for the treatment of moderate-to-severe $\mathrm{AD}$ ) was used as reference compound. Oral administration of MPT0G211 significantly ameliorated memory impairment (Fig. 6a). Immunohistochemical analysis revealed that mutant transgenes mediated increases in total tau and tau phosphorylation at Ser396/Ser404 in the hippocampal CA1 region of mice that harbor tau ${ }_{\mathrm{P} 301 \mathrm{~L}}$ mutant transgene; MPT0G211 treatment significantly downregulated p-Tau (S396) and p-Tau (S404) expression and increased acetyl- $\alpha$-tubulin accumulation in the $3 \times \mathrm{Tg}-\mathrm{AD}$ mice brain (Fig. 6b). Western blot analysis also demonstrated similar results (Fig. 6c). These results provide strong support that MPT0G211 treatments can ameliorate Alzheimer's deficits.

Successful crossing of the BBB by therapeutic drugs is essential in the treatment of CNS disorders. To explore whether MPT0G211 can penetrate into the brain, single oral administration of MPT0G211 was performed, and plasma and brain samples were collected and analyzed by liquid chromatography tandem mass spectrometry (LCMS/MS) to obtain brain/plasma ratios. As observed, MPT0G211 was detected in brain samples $1 \mathrm{~h}$ after administration, and the brain/plasma ratio was 1.01 (Table 1). Concentrations of MPT0G211 were detected in the brain for at least $3 \mathrm{~h}$. These results clearly indicated that MPT0G211 can penetrate the BBB, where it potentially ameliorates learning and memory deficits. A summary of the proposed neuroprotective mechanism of MPT0G211 is illustrated in Fig. 7.

\section{Discussion}

Hyperphosphorylated tau can aggregate into filaments, and these tau filaments can continue to aggregate and form insoluble deposits, which are referred to as NFTs. This accumulation of abnormal proteins results in neurotoxicity in the brain, leading to AD. Thus inhibiting tau phosphorylation and promoting phosphorylated tau degradation remain the main goals of $\mathrm{AD}$ treatment ${ }^{2}$. Previous studies have demonstrated that HDAC6 is involved in the process of tau hyperphosphorylation ${ }^{6,7}$, and increased HDAC6 levels are found in the hippocampus and cortex of the AD brain ${ }^{6}$. Reducing HDAC6 activity has been reported to ameliorate cognitive deficits in an AD mouse model ${ }^{7,17}$. Mice lacking HDAC6 survive well and develop normally ${ }^{9}$, suggesting that pharmacological inhibition of this enzyme may not cause severe side effects. Collectively, these results suggest that HDAC6 may be a novel, promising target of AD.

APP 695 is a plasma membrane protein known to be the source of $A \beta^{12,22}$. Recent studies have indicated that significant $A \beta_{1-40}$ and $A \beta_{1-42}$ can be detected in APP 695overexpressing neuronal cells, and $A \beta$ can increase the tau hyperphosphorylation and decrease the solubility of tau $^{23,24}$. In addition, transfecting tau P301L into cells results in proteins that are more favorable substrates for phosphorylation by protein kinases, increases tau phosphorylation, and also dramatically enhances the tendency for aggregation and polymerization into filaments, with resulting neuronal dysfunction ${ }^{13,17,25}$. In contrast, reducing the phosphorylation of tau at Ser199/Ser202 and Ser396/Ser404 appears to restore the tau-microtubule assembly ${ }^{26}$. In addition, by using different phosphorylated 
A

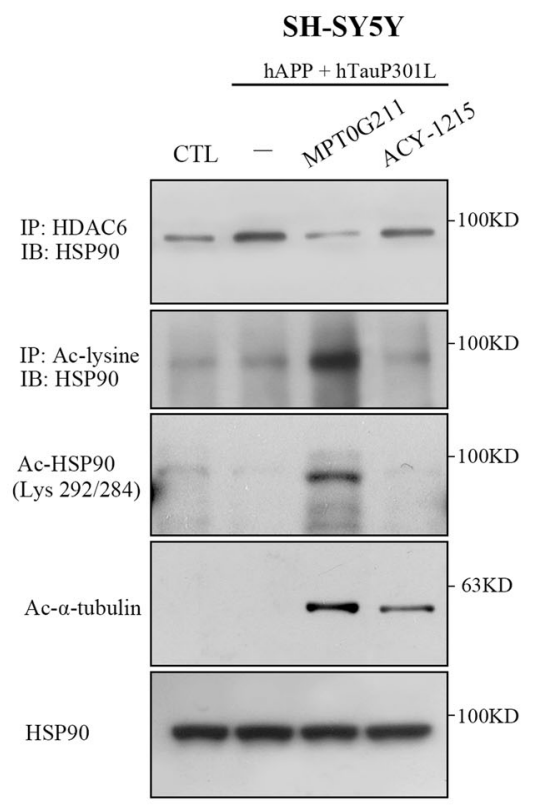

B

SH-SY5Y hAPP + hTauP301L
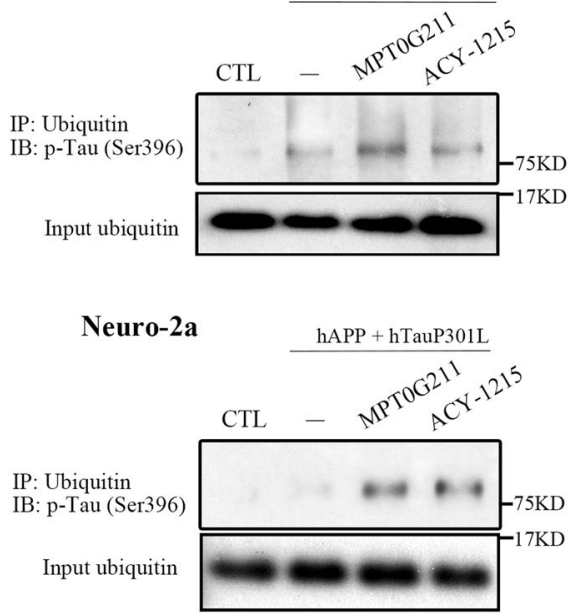

C
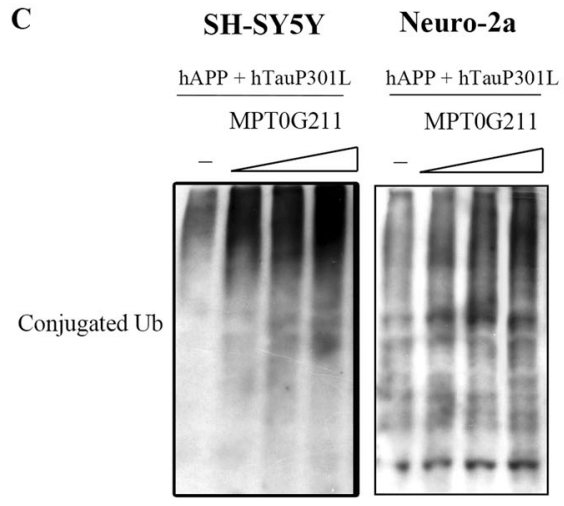

Neuro-2a

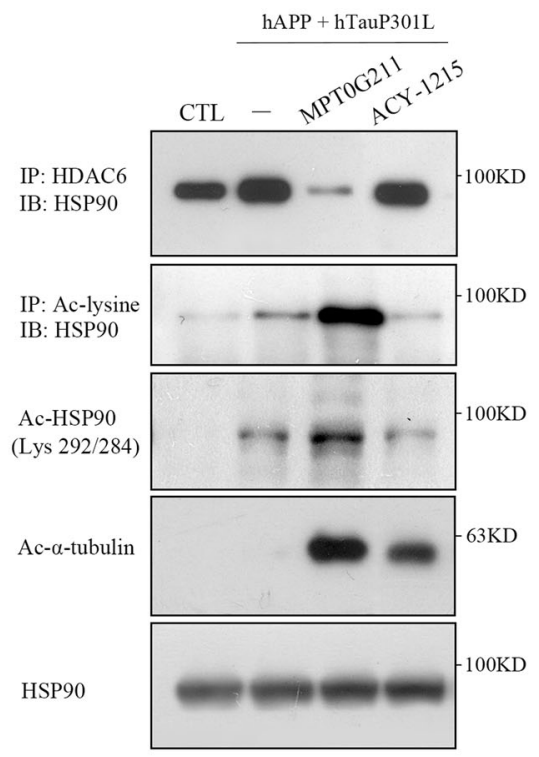

D

\section{SH-SY5Y}

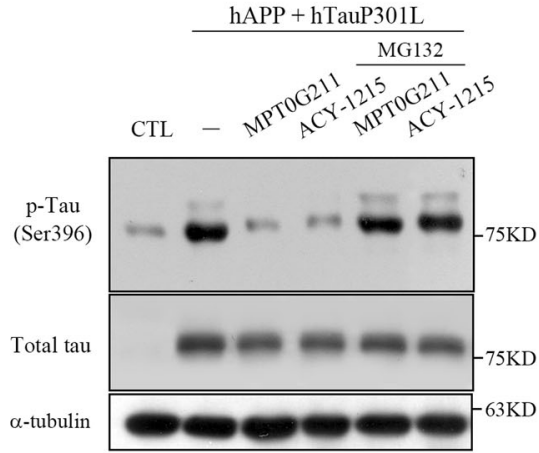

Neuro-2a

hAPP + hTauP301L

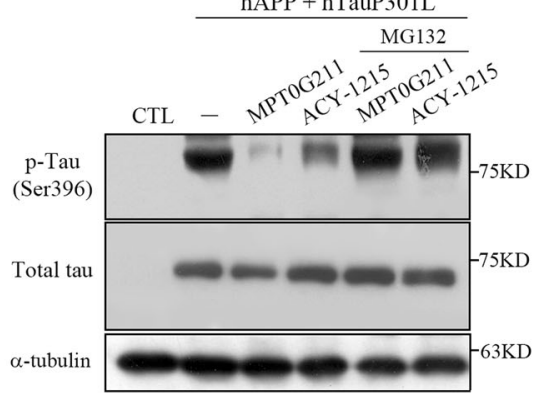

Fig. 4 (See legend on next page.) 
(see figure on previous page)

Fig. 4 MPTOG211 increased the ubiquitination of $\mathbf{p}$-tau and degradation by proteasome. $\mathbf{a}, \mathbf{b}$ SH-SY5Y and Neuro-2a cells were transfected for

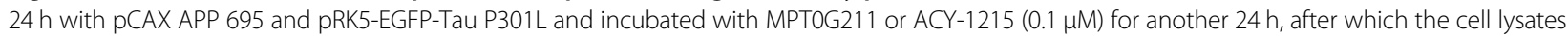
were immunoprecipitated with antibodies against HDAC6, acetyl-lysine (a) or ubiquitin (b) and were subjected to immunoblotting. c Cells were transfected with PCAX APP 695 and pRK5-EGFP-Tau P301L for $24 \mathrm{~h}$ and were then incubated with MPTOG211 (0.01-1 $\mu \mathrm{M})$ for another $24 \mathrm{~h}$. Immunoblots reveal polyubiquitin complexes. d pCAX APP 695 or pRK5-EGFP-Tau P301L were used to transfect the cells for $24 \mathrm{~h}$, incubated with or without MG132 $(1 \mu \mathrm{M})$ for $30 \mathrm{~min}$, and were then treated with MPTOG211 or ACY-1215 (0.1 $\mu \mathrm{M})$ for another $24 \mathrm{~h}$. Cell lysates were prepared for western blot analysis of the indicated proteins

tau variants, it has been found that p-tau is toxic to the cultured cells ${ }^{27}$.An animal model for tauopathy has also revealed that $\mathrm{p}$-tau is the primary factor for cellular toxicity $^{28}$. In this study, the cells co-transfected with hAPP 695 and hTau P301L resulted in significant increases in the phosphorylation of tau Ser396/Ser404 (Fig. 5a) and aggregation (Fig. 3a), which then resulted in apoptosis (Fig. 3b-d). Our results also revealed that MPT0G211 treatment not only significantly inhibited the tau phosphorylation of tau Ser396/Ser404, aggregation, and subsequent apoptosis, but also penetrated the BBB (Table 1) and ameliorated learning and memory impairment in an animal model (Fig. 6).

The UPS is responsible for degrading the majority of cellular proteins and maintaining protein homeostasis. During this process, molecular chaperones act as specialized machinery for assisting protein folding. A recent study has indicated that molecular chaperones may also be involved in $\mathrm{AD}$ pathology, and increasing evidence indicates that Hsp-UPS-mediated aggregate clearance is the pivotal mechanism of $\mathrm{AD}$ treatment ${ }^{16}$. Hsp90 is a major Hsp that interacts with diverse proteins, including tau, and previous studies have indicated that hyperphosphorylated tau can be recognized by $\mathrm{Hsp} 90^{17,29}$. Following binding with Hsp90, the specific components of the Hsp90 complex determine whether the client proteins enter a refolding pathway or are targeted for degradation by the UPS ${ }^{17}$. In the ADP-bound conformation, Hsp90 associates with the client-bound Hsp70/Hsp40 complex and recruits the ubiquitin ligase carboxy terminus of Hsp70-interacting protein, directing the client to proteasomes for degradation ${ }^{16}$. Replacement of ADP with ATP can alter Hsp90 conformation, resulting in the release of Hsp70/Hsp40 and allowing the recruitment of p23, which can stabilize the client proteins ${ }^{16}$. A recent study has indicated that the acetylation state of Hsp90 modulates the function of $\mathrm{Hsp} 90^{30}$. For example, hyperacetylated Hsp90 reduces the affinity of Hsp90 binding to the protein complex, which leads to impairment in the chaperone function and promotes client protein degradation ${ }^{17,18,30}$. Bali and Nimmanapalli groups have demonstrated that depletion of HDAC6 levels, or the inhibition of its deacetylase activity, results in hyperacetylation of Hsp90 associated with inhibition of ATP and client protein binding to Hsp90, eventually leading to polyubiquitylation and proteasome degradation of client proteins ${ }^{31,32}$. In this study, MPT0G211 treatment significantly increased the hyperacetylation of Hsp90 and p-tau (Ser396) ubiquitination (Fig. 4a, b). In addition, proteasome inhibitor MG132 treatment clearly reversed the inhibition of p-tau caused by MPT0G211 (Fig. 4d). These results are consistent with the previous studies and indicate that MPT0G211 augments the polyubiquitination of p-tau and subsequent degradation.

We also evaluated whether MPT0G211 plays a role in the modulation of kinase activities involved in the phosphorylation of tau. Among numerous kinases that have been implicated in tau phosphorylation, GSK3 $\beta$ and CDK5 have been identified as prime candidates for aberrant tau hyperphosphorylation at disease-associated sites $^{19,20}$. In this study, inhibition of p-tau Ser396 by MPT0G211 treatment was not associated with changes in the CDK5 expression (Fig. 5a); however, it was associated with phospho-GSK3 $\beta$ increasing on Ser9 (Fig. 5b). GSK3 $\beta$ is a constitutively active protein kinase and its regulation is primarily based on the inhibition of its activity by phosphorylation on $\operatorname{Ser} 9^{19}$; activation of the phosphoinositide-3 kinase (PI3K)/Akt pathway has been identified to suppress GSK3 $\beta$ activity via Ser9 phosphorylation by $\mathrm{Akt}^{33}$. GSK3 $\beta$ activity is increased in the brain of AD patients, and overexpression of GSK3 $\beta$ in mice results in tau hyperphosphorylation and $\mathrm{AD}$-like tau pathology ${ }^{34,35}$. Phosphorylation of tau by GSK3 $\beta$ occurs in the regions surrounding the microtubule-binding domain, whereas phosphorylation at these sites has been found to cause tau detachment from microtubules and lead to selfaggregation $^{36}$. In addition, a previous study has demonstrated that exposure of neurons to $A \beta$ increases GSK3 $\beta$ activity through the inhibition of PI3K signals, and blockade of GSK3 $\beta$ activity can prevent A $\beta$-induced neurodegeneration $^{37}$. Herein, significant p-GSK3 $\beta$ increases on Ser9 through Akt phosphorylation were associated with p-tau Ser396 in response to MPT0G211; another p-GSK3 $\beta$ on Ser216 decreasing was also observed (Fig. 5b). In addition, our results also demonstrated that MPT0G211 treatment diminishes GSK3 $\beta$ activity in $A \beta_{1-40}$-induced tau phosphorylation (Fig. 5c). Furthermore, we also revealed that MPT0G211 can penetrate the BBB (Table 1), and oral administration of MPT0G211 significantly ameliorated memory impairment 


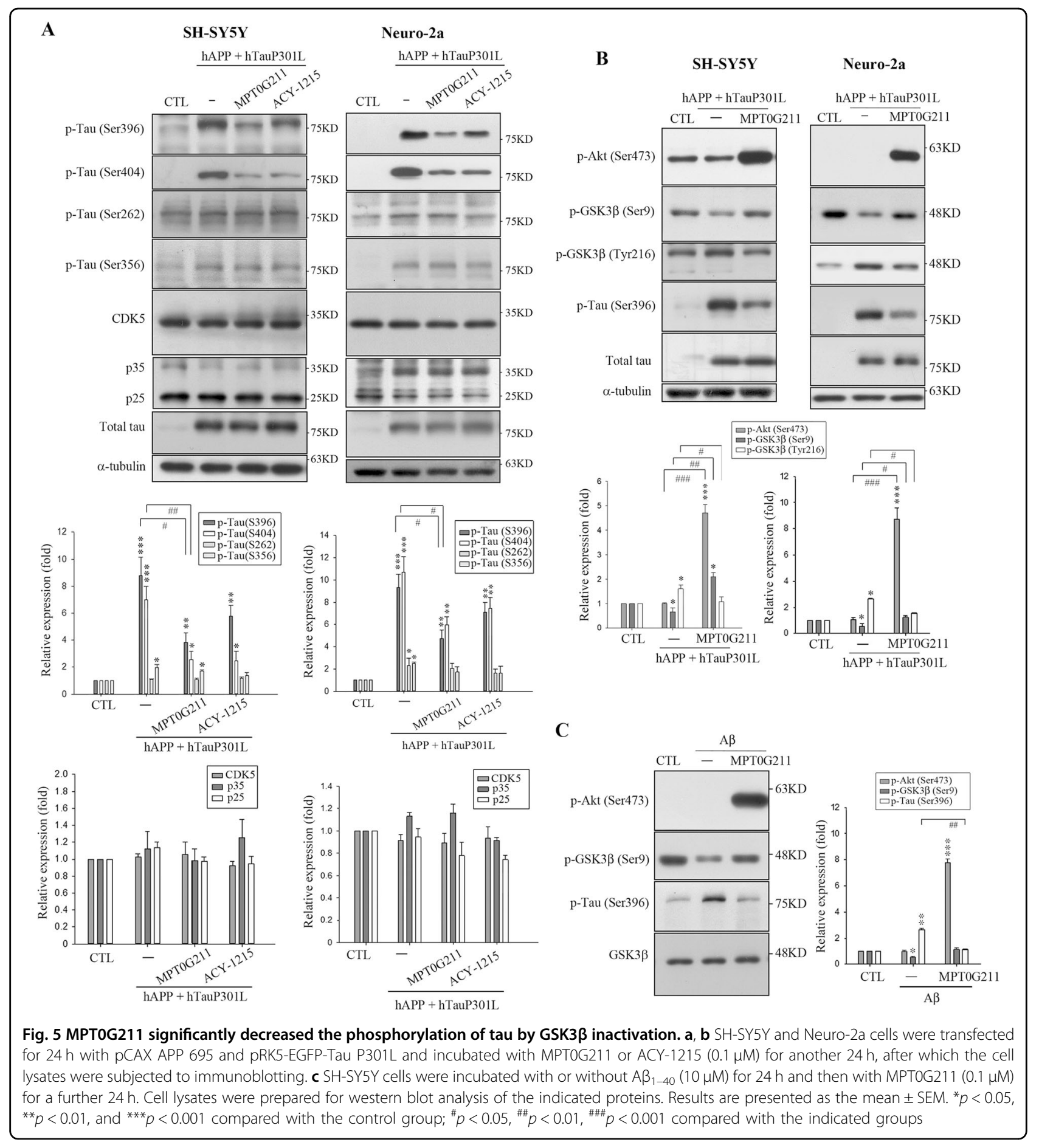

and tau phosphorylation (Fig. 6). Collectively, our novel results suggest that MPT0G211 has a high potential as an $\mathrm{AD}$ treatment agent.

\section{Materials and methods}

\section{Cell lines}

The human neuroblastoma cell line SH-SY5Y, kindly provided by Professor Shiow-Lin Pan (Ph.D. Program for
Cancer Molecular Biology and drug Discovery, Taipei Medical University), was maintained in Ham's F12 nutrient mixture/Minimum essential media with $10 \%$ fetal bovine serum, penicillin (100 units/mL), and streptomycin $(100 \mu \mathrm{g} / \mathrm{mL})$. The mouse neuroblastoma cell line Neuro2a, which was purchased from the Bioresource Collection and Research Center (Hsinchu, Taiwan), was cultured in Minimum essential media containing 10\% fetal bovine 
A

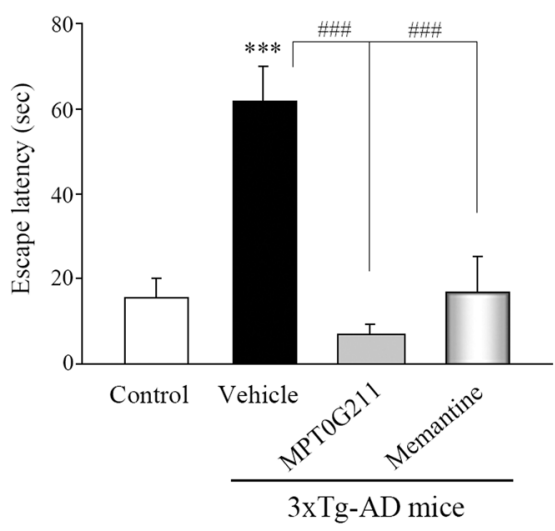

C

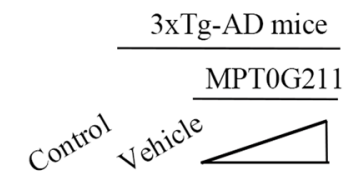

p-Tau (Ser396)

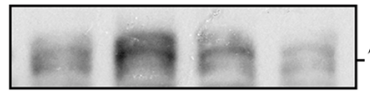
$-75 \mathrm{KD}$

p-Tau (Ser404)

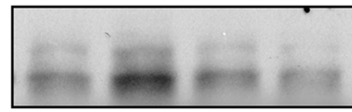
$75 \mathrm{KD}$

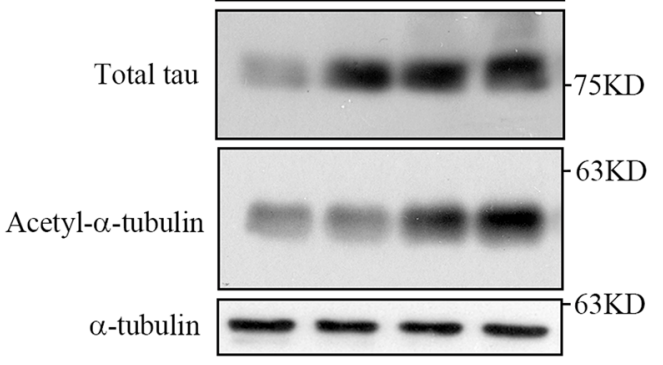

B

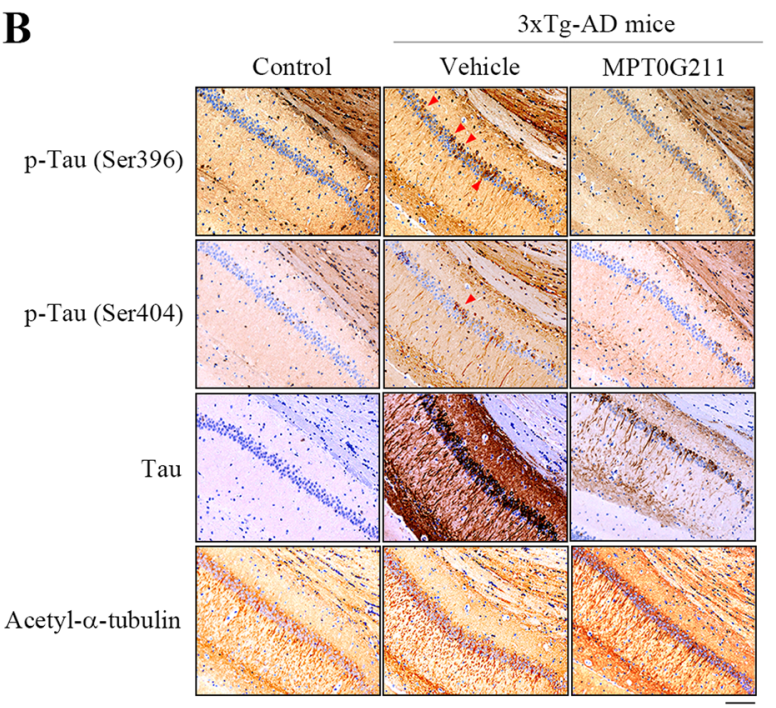

$25 \mu \mathrm{m}$

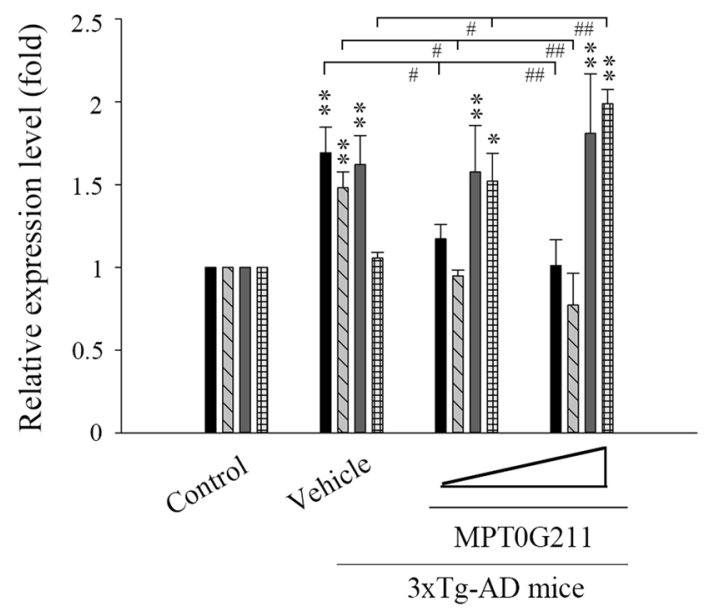

Fig. 6 MPTOG211 significantly ameliorated the spatial memory impairment in vivo. a 3XTg-AD mice (aged 6 months) were orally administered MPTOG211 (50 mg/kg) or memantine $(30 \mathrm{mg} / \mathrm{kg})$ daily for 3 months; mice were then subjected to the Morris water maze, and their escape latency times were measured. b, c 3XTg-AD mice were orally administered MPTOG211 (50, $100 \mathrm{mg} / \mathrm{kg})$ for 3 months, then mice were sacrificed and their brains were removed for immunohistochemical analysis for acetyl-a-tubulin expression and tau phosphorylation (Ser396, Ser404) in the CA1 region of the hippocampus (b) and western blot analysis (c). Red arrowheads indicate phosphorylated-tau proteins. Scale bar $=25 \mu \mathrm{m}$. Data represent the mean \pm SEM. ${ }^{*} p<0.05,{ }^{* *} p<0.01$, and ${ }^{* *} p<0.001$ compared with the basal or control group; ${ }^{\#} p<0.05,{ }^{\# \#} p<0.01$, and ${ }^{\# \# \#} p<0.001$ compared with the vehicle-treated group

Table 1 Brain and plasma concentrations of MPTOG211 after oral administration in rats

\begin{tabular}{lllllll}
\hline Compound & Route & Dose $(\mathbf{m g} / \mathbf{k g})$ & Time $(\mathbf{h})$ & Brain concentration $(\mathbf{n g} / \mathbf{g})$ & Plasma concentration (ng/g) & Brain/plasma ratio \\
\hline MPTOG211 & PO & 50 & 1 & $56.9 \pm 3.4$ & $56.4 \pm 4.0$ & 1.01 \\
& PO & 50 & 3 & $11.0 \pm 0.1$ & $12.2 \pm 1.4$ & 0.90 \\
\hline
\end{tabular}




\section{Without MPT0G211}

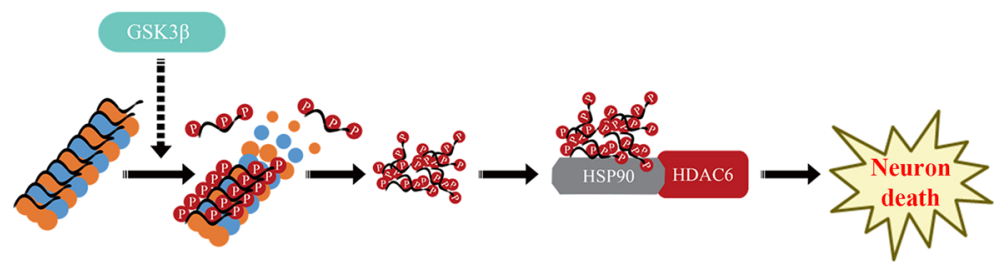

With MPT0G211

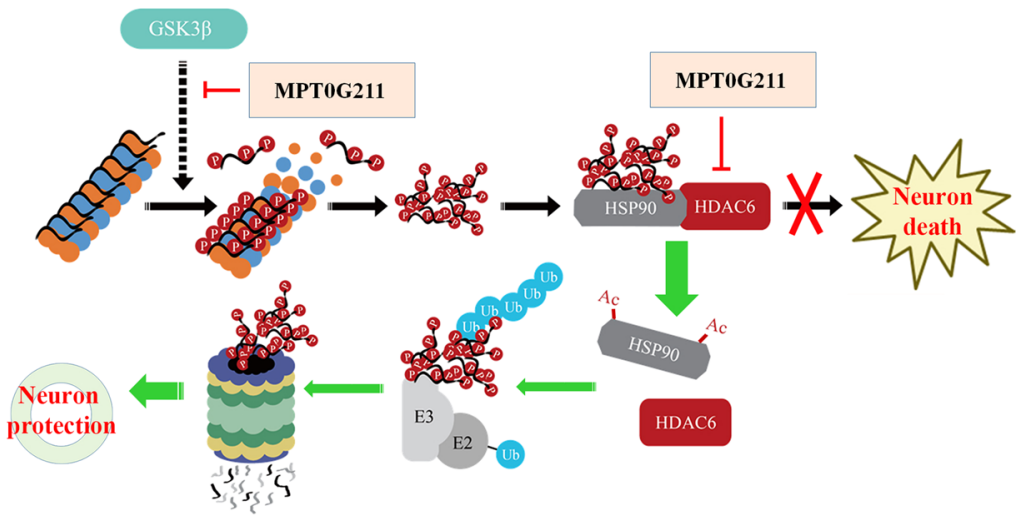

Fig. 7 Summary of the proposed mechanism of the neuroprotective effect of MPTOG211. Tau phosphorylation can be facilitated by GSK33, lead to p-tau aggregation, and cause neuron death. MPTOG211 treatment not only diminished tau phosphorylation by inhibition GSK3 $\beta$ activity but also enhanced the acetylation of Hsp90, which caused the downregulation of HDAC6/Hsp90 binding and facilitated proteasomal degradation of polyubiquitinated p-tau

serum, penicillin, and streptomycin. All cell lines were incubated in an atmosphere containing $5 \% \mathrm{CO}_{2}$ at $37^{\circ} \mathrm{C}$.

\section{Materials}

MPT0G009 and SAHA were synthesized by Professor Jing-Ping Liou to $>98 \%$ purity $^{11}$. Primary antibodies against APP, acetyl-histone 3, histone 3, $\alpha$-tubulin, acetyl$\alpha$-tubulin, Hsp90, HDAC6, acetyl-lysine, p-Akt (Ser473), p-GSK3 $\beta$ (Ser9), and p-GSK3 $\beta$ (Tye216) were purchased from Cell Signaling Technology (Danvers, MA, USA). Antibodies to p-tau (Ser396) and p-tau (Ser404) were purchased from Abcam (Cambridge, MA, USA); antibodies to p-tau (Ser262) and p-tau (Ser356) were obtained from Thermo Fisher Scientific (Waltham, MA, USA). An antibody against ubiquitin was purchased from Santa Cruz Biotechnology, Inc. (Dallas, TX, USA). A $\beta_{1-40}$ was purchased from AnaSpec (Fremont, CA, USA). The labeled secondary antibodies were horseradish peroxidase (HRP)-conjugated anti-mouse and anti-rabbit IgG antibodies (Jackson ImmunoResearch Inc., West Grove, PA, USA). The pCAX FLAG APP and pRK5-EGFP-Tau P301L plasmids were provided by Dennis Selkoe and Tracy Young-Pearse (Addgene plasmid \#30154) and Karen Ashe (Addgene plasmid \#46908), respectively. TurboFect transfection reagent was from Fermentas
(Burlington, Ontario, Canada). ACY-1215 was purchased from BioVision Inc. (Milpitas, CA, USA). Unless otherwise stated, all other chemicals were purchased from Sigma-Aldrich (St. Louis, MO, USA).

\section{Transfection assay}

Cells were seeded 1 day before transfection. The plasmids pCAX FLAG APP and pRK5-EGFP-Tau P301L $(1 \mu \mathrm{g}$ each) and $1 \mu \mathrm{L}$ of TurboFect transfection reagent were mixed for $20 \mathrm{~min}$ at room temperature, added to the cells, and the suspensions were incubated for $24 \mathrm{~h}$ at $37^{\circ} \mathrm{C}$ in a humidified atmosphere containing $5 \% \mathrm{CO}_{2}$.

\section{Flow cytometry}

After drug treatment, the cells were collected, washed with cold phosphate-buffered saline (PBS), and fixed with $75 \%$ alcohol overnight at $-20^{\circ} \mathrm{C}$. After centrifugation, the fixed cells were washed with cold PBS and resuspended in DNA extraction buffer $\left(0.2 \mathrm{M} \mathrm{Na}_{2} \mathrm{HPO}_{4}, 0.1 \mathrm{M}\right.$ citric acid, $\mathrm{pH}$ 7.8) for $30 \mathrm{~min}$. The cells were centrifuged and incubated with propidium iodide (PI) (0.1\% Triton X-100, 100 $\mu \mathrm{g} / \mathrm{mL}$ RNase A, and $80 \mu \mathrm{g} / \mathrm{mL}$ PI in PBS) for $30 \mathrm{~min}$. The cell cycle was analyzed using a FACScan Flow cytometer and Cell Quest software (Becton Dickinson, Mountain View, CA, USA). 


\section{Immunoblot and immunoprecipitation analyses}

Cells $\left(1 \times 10^{6}\right)$ were incubated for $10 \mathrm{~min}$ at $4{ }^{\circ} \mathrm{C}$ in lysis buffer (20 mM HEPES, pH 7.4, 2 mM EGTA, $50 \mathrm{mM} \beta$ glycerophosphate, $0.1 \%$ Triton $\mathrm{X}-100,10 \%$ glycerol, $1 \mathrm{mM}$ dithiothreitol, $1 \mu \mathrm{g} / \mathrm{mL}$ leupeptin, $5 \mu \mathrm{g} / \mathrm{mL}$ aprotinin, 1 $\mathrm{mM}$ phenylmethylsulfonyl fluoride, and $1 \mathrm{mM}$ sodium orthovanadate), scraped from the plate, incubated on ice for $10 \mathrm{~min}$, and centrifuged at $17,000 \times g$ for $30 \mathrm{~min}$ at $4^{\circ}$ C. Protein samples $(30 \mu \mathrm{g})$ were electrophoresed through sodium dodecyl sulfate-polyacrylamide gels (SDS-PAGE) and transferred onto a nitrocellulose membrane, which was then blocked by incubation for $30 \mathrm{~min}$ at room temperature with $5 \%$ fat-free milk in PBS. Immunoblotting was performed by overnight incubation at $4{ }^{\circ} \mathrm{C}$ with primary antibodies in PBS, followed by incubation for $1 \mathrm{~h}$ at room temperature with HRP-conjugated secondary antibodies. Bound antibodies were measured using ECL reagent (T-Pro Biotechnology, New Taipei City, Taiwan), and the membrane was placed on a photographic film. Cell lysates $(30 \mu \mathrm{g})$ were incubated with antibodies $(1 \mu \mathrm{g}$ each) and protein A/G agarose beads overnight at $4{ }^{\circ} \mathrm{C}$. The precipitated beads were washed three times with $1 \mathrm{~mL}$ of ice-cold cell lysis buffer, and bound immune complexes were separated using 8\% SDS-PAGE, followed by immunoblotting using the indicated primary antibody.

\section{Subcellular fractionation}

This assay followed a published method ${ }^{6}$. Briefly, cells $\left(1 \times 10^{7}\right)$ were treated with drugs for $24 \mathrm{~h}$ and scraped off into breaking buffer $(0.25 \mathrm{M}$ sucrose, $10 \mathrm{mM}$ HEPES, $\mathrm{pH}$ 7.2, $1 \mathrm{mM} \mathrm{MgAc}$, and protease inhibitors). The lysate was centrifuged at $190,000 \times g$ for $1 \mathrm{~h}$, and the supernatant was collected as the cytosolic fraction. The pellet was resuspended and incubated with $5 \mu \mathrm{M}$ nocodazole on ice for $30 \mathrm{~min}$ and then centrifuged for $1 \mathrm{~h}$ at 190,000 $\times g$. The supernatant contained microtubule-tau, and the pellets contained membrane-bound and aggregated tau. The pellets were further extracted using $100 \mathrm{mM}$ sodium carbonate buffer, $\mathrm{pH} 11.5$, centrifuged at $190,000 \times g$ for 1 $\mathrm{h}$, and washed with $1 \%$ SDS to produce a fraction containing tau aggregates. Samples containing equal amounts of protein were analyzed using SDS-PAGE.

\section{Analysis of cognitive dysfunction}

Six-month-old female B6;129-Psen $1^{\text {tm } 1 M p m} \mathrm{Tg}$ (APPSwe, tauP301L)1Lfa/Mmjax (3xTg-AD) mice and control B6129SF2/J mice were obtained from the Jackson Laboratory (Bar Harbor, ME, USA), orally administered MPT0G211 $(50 \mathrm{mg} / \mathrm{kg})$ or memantine $(30 \mathrm{mg} / \mathrm{kg}$, dissolved in water) once daily for 3 months, and then subjected to Morris water maze. The assay that using 3xTgAD mice was entrusted to carry out by Development Center for Biotechnology (New Taipei City, Taiwan).

\section{Morris water maze}

The water maze was constructed as a white circular pool filled with water, and the water temperature was maintained at $23-27^{\circ} \mathrm{C}$. A white platform was established and submerged $5 \mathrm{~cm}$ below the surface of the water and styrofoam beads were added to make the platform invisible. Animals were trained by permitting them to stay for $10 \mathrm{~s}$ upon reaching the platform. If the animals failed to locate the platform in $180 \mathrm{~s}$, it was placed on the platform for $10 \mathrm{~s}$ to learn and memorize the location of the platform. Training was performed twice daily and 4 days during 1 week. Test trials were repeated twice with a 20 min interval for each animal. Scopolamine $(1 \mathrm{mg} / \mathrm{kg})$ was injected intraperitoneally $90 \mathrm{~min}$ before the test trial to induce $\mathrm{AD}$-like features, except for the control group.

\section{Elevated plus maze}

The plus maze consisted of two open and two closed arms, connected by a central platform. Animals were individually placed at the end of either of the open arms facing away from the central platform. The time for each rat to move from the open arm to either of the closed arms was recorded. If the rat did not enter the closed arm within $180 \mathrm{~s}$, it was gently pushed into the closed arm and assigned a transfer latency equal to $180 \mathrm{~s}$. These experiments were performed in accordance with relevant ethics guidelines and regulations, which were reviewed and approved by the Animal Use and Management Committee of the College of Medicine, National Taiwan University (IACUC number: 20130361).

\section{BBB crossing assay}

This assay was performed by Eurofins Scientific. Briefly, SD rats weighing 200-300 g were provided by BioLasco Taiwan (under the license of Charles River Laboratories). Rats were sedated under general inhalant anesthesia (3\% isoflurane) for blood collection using cardiac puncture 60 and $180 \mathrm{~min}$ after oral administration of the test compound. Aliquots of blood were gently mixed with lithium heparin, kept on ice, and centrifuged at $2500 \times g$ for 15 $\min$ at $4{ }^{\circ} \mathrm{C}$. The plasma was then harvested and stored at $-70^{\circ} \mathrm{C}$. After blood sampling, rats were decapitated, and the entire brain was quickly removed and rinsed with cold saline $(0.9 \% \mathrm{NaCl}, \mathrm{w} / \mathrm{v})$. The surface vasculature was ruptured, blotted with dry gauze, weighed, and stored on ice within $1 \mathrm{~h}$ of collection. Each brain was homogenized in $3 \mathrm{~mL}$ cold PBS, $\mathrm{pH} 7.4$, for $10 \mathrm{~s}$ on ice, and centrifuged at $5400 \times g$ for $15 \mathrm{~min}$ at $4{ }^{\circ} \mathrm{C}$. Supernatants were precipitated using acetonitrile precipitation and subjected to high-performance LC-MS/MS.

\section{Data analysis and statistics}

Each result represents the mean \pm SEM of at least three independent experiments. The data were analyzed using 
the Student's $t$-test. One-way analysis of variance was performed to analyze the animal data. Parameters with a $p$-value $<0.05$ were considered statistically significant.

\section{Acknowledgements}

This work was supported by a grant from the Ministry of Science and Technology of Taiwan (MOST 105-2325-B-002-039; MOST 106-2320-B-002-006MY3).

\section{Conflict of interest}

The authors declare that they have no conflict of interest.

\section{Publisher's note}

Springer Nature remains neutral with regard to jurisdictional claims in published maps and institutional affiliations.

Received: 9 February 2018 Revised: 13 April 2018 Accepted: 26 April 2018 Published online: 29 May 2018

\section{References}

1. Kurz, A. \& Perneczky, R. Novel insights for the treatment of Alzheimer's disease. Prog. Neuropsychopharmacol. Biol. Psychiatry 35, 373-379 (2011).

2. Anand, R., Gill, K. D. \& Mahdi, A. A. Therapeutics of Alzheimer's disease: past. Neuropharmacology 76, 27-50 (2014).

3. Kumar, A., Singh, A. \& Ekvali. A review on Alzheimer's disease pathophysiology and its management: an update. Pharmacol. Rep. 67, 195-203 (2015).

4. Lloret, A., Fuchsberger, T., Giraldo, E. \& Viña, J. Molecular mechanisms linking amyloid $\beta$ toxicity and Tau hyperphosphorylation in Alzheimer's disease. Free Radic. Biol. Med. 83, 186-191 (2015).

5. Valenzuela-Fernandez, A., Cabrero, J. R., Serrador, J. M. \& Sanchez-Madrid, F. HDAC6: a key regulator of cytoskeleton, cell migration and cell-cell interactions. Trends Cell Biol. 18, 291-297 (2008).

6. Ding, H., Dolan, P. J. \& Johnson, G. V. Histone deacetylase 6 interacts with the microtubule-associated protein tau. J. Neurochem. 106, 2119-2130 (2008).

7. Govindarajan, N. et al. Reducing HDAC6 ameliorates cognitive deficits in a mouse model for Alzheimer's disease. EMBO Mol. Med. 5, 52-63 (2013).

8. Yu, C. W., Chang, P. T., Hsin, L. W. \& Chern, J. W. Quinazolin-4-one derivatives as selective histone deacetylase- 6 inhibitors for the treatment of Alzheimer's disease. J. Med. Chem. 56, 6775-6791 (2013).

9. Zhang, Y. et al. Mice lacking histone deacetylase 6 have hyperacetylated tubulin but are viable and develop normally. Mol. Cell. Biol. 28, 1688-1701 (2008).

10. Odagiri, S. et al. Brain expression level and activity of HDAC6 protein in neurodegenerative dementia. Biochem. Biophys. Res. Commun. 430, 394-399 (2013).

11. Lee, H. Y. et al. (N-Hydroxycarbonylbenylamino)quinolines as selective histone deacetylase 6 inhibitors suppress growth of multiple myeloma in vitro and in vivo. J. Med. Chem. https://doi.org/10.1021/acs.jmedchem.7b01404 (2018).

12. Young-Pearse, T. L. et al. A critical function for beta-amyloid precursor protein in neuronal migration revealed by in utero RNA interference. J. Neurosci. 27, 14459-14469 (2007).

13. Hoover, B. R. et al. Tau mislocalization to dendritic spines mediates synaptic dysfunction independently of neurodegeneration. Neuron 68, 1067-1081 (2010).

14. Simic, G. et al. Tau protein hyperphosphorylation and aggregation in Alzheimer's disease and other tauopathies, and possible neuroprotective strategies. Biomolecules 6, 6 (2016).

15. Dou, F. et al. Chaperones increase association of tau protein with microtubules. Proc. Natl. Acad. Sci. USA 100, 721-726 (2003).
16. Sulistio, Y. A. \& Heese, K. The ubiquitin-proteasome system and molecular chaperone deregulation in Alzheimer's disease. Mol. Neurobiol. 53, 905-931 (2016).

17. Cook, C. et al. Loss of HDAC6, a novel CHIP substrate, alleviates abnormal tau accumulation. Hum. Mol. Genet. 21, 2936-2945 (2012).

18. Kovacs, J. J. et al. HDAC6 regulates Hsp90 acetylation and chaperonedependent activation of glucocorticoid receptor. Mol. Cell 18, 601-607 (2005).

19. Lei, P., Ayton, S., Bush, A. I. \& Adlard, P. A. GSK-3 in neurodegenerative disease Int. J. Alzheimers Dis. 2011, 189246 (2011).

20. Lee, M. S. \& Tsai, L. H. Cdk5: one of the links between senile plaques and neurofibrillary tangles? J. Alzheimers Dis. 5, 127-137 (2003).

21. Takashima, A., Noguchi, K., Sato, K., Hoshino, T. \& Imahori, K. Tau protein kinase I is essential for amyloid $\beta$-protein-induced neurotoxicity. Proc. Natl. Acad. Sci. USA 90, 7789-7793 (1993)

22. Anandatheerthacarada, H. K. Biswas, G., Robin, M. A. \& Avadhani, N. G. Mitochondrial targeting and a novel transmembrane arrest of Alzheimer's amyloid precursor protein impairs mitochondrial function in neuronal cells. J. Cell. Biol. $161,41-54$ (2003)

23. Lin, N. et al. Tripchlorolide attenuates $\beta$-amyloid generation via suppressing PPARy-regulated BACE1 activity in N2a/APP695 cells. Mol. Neurobiol. 53, 6397-6406 (2016)

24. Wang, Y. P. et al. Endogenous overproduction of beta-amyloid induces tau hyperphosphorylation and decreases the solubility of tau in N2a cells. J. Neural. Transm. Nienna) 113, 1723-1732 (2006).

25. Alonso Adel, C., Mederlyova, A., Novak, M., Grundke-lqbal, I. \& Iqbal, K. Promotion of hyperphosphorylation by frontotemporal dementia tau mutations. J. Biol. Chem. 279, 34873-34881 (2004)

26. Wang, J. Z., Gong, C. X., Zaidi, T., Grundke-lqbal, I. \& lqbal, K. Dephosphorylation of Alzheimer paired helical filament by protein phosphatase-2A and -2B. J. Biol. Chem. 270, 4854-4860 (1995).

27. Brandt, R., Hundelt, M. \& Shahani, N. Tau alteration and neuronal degeneration in taupathies: mechanisms and models. Biochim. Biophys. Acta 1739, 331-354 (2005).

28. Lim, F. et al. FTDP-17 mutation in tau transgenic mice provoke lysosomal abnormalities and tau filaments in forebrain. Mol. Cell. Neurosci. 18, 702-714 (2001).

29. Dickey, C. A. et al. The high-affinity HSP90-CHIP complex recognizes and selectively degrades phosphorylated tau client proteins. J. Clin. Invest. 117, 648-658 (2007).

30. Scroggins, B. T. et al. An acetylation site in the middle domain of Hsp90 regulates chaperone function. Mol. Cell 25, 151-159 (2007).

31. Bali, P. et al. Inhibition of histone deacetylase 6 acetylates and disrupts the chaperone function of heat shock protein 90. J. Biol. Chem. 280, 26729-26734 (2005).

32. Nimmanapalli, R. et al. Histone deacetylase inhibitor LAQ824 both lowers expression and promotes proteasomal degradation of Bcr-Abl and induces apoptosis of imatinib mesylate-sensitive or -refractory chronic myelogenous leukemia-blast crisis cells. Cancer Res. 63, 5126-5135 (2003).

33. Wang, $Y$. et al. Cross talk between PI3K-AKT-GSK-3 $\beta$ and PP2A pathways determines tau hyperphosphorylation. Neurobiol. Aging 36, 188-200 (2015).

34. Leroy, K., Yilmaz, Z. \& Brion, J. P. Increased level of active GSK-3ß in Alzheimer's disease and accumulation in argyrophilic grains and in neurons at different stages of neurofibrillary degeneration. Neuropathol. Appl. Neurobiol. 33, 43-55 (2007).

35. Engel, $T$. et al. Cooexpression of FIDP-17 tau and GSK-3 3 in transgenic mice induce tau polymerization and neurodegeneration. Neurobiol. Aging 27, 1258-1268 (2006).

36. Hernández, F., Gómez de Barreda, E., Fuster-Matanzo, A., Lucas, J. J. \& Avila, J. GSK3: a possible link between beta amyloid peptide and tau protein. Exp. Neurol. 223, 322-325 (2010).

37. Takashima, A. et al. Exposure of rat hippocampal neurons to amyloid beta peptide (25-35) induces the inactivation of phosphatidyl inositol-3 kinase and the activation of tau protein kinase I/glycogen synthase kinase-3ß. Neurosci. Lett. 203, 33-36 (1996). 